Original Contribution

\title{
A CONCEPT FOR INCLUSIVE PHYSICAL EDUCATION TRAINING PROGRAM FOR FUTURE PRE-SCHOOL AND PRIMARY-SCHOOL TEACHERS
}

\author{
G. Terzieva* \\ Faculty of Education, Trakia University, Stara Zagora, Bulgaria
}

\begin{abstract}
The adoption of new normative documents in the field of education in Bulgaria determines the inclusion of children with special educational needs in general education schools. The significant and integral role which physical education plays in the educational process poses the question of the inclusion of children with impairments in motor activity training as well. Teachers implementing it contribute greatly to its positive effects.

The main features of physical education include active motor activity and the related physical workload. In order for them to be adapted successfully to the specific needs of children with different disabilities, more specialized training is required.

The analysis of the curricula of the faculties of education in Bulgaria shows that future pre-school and primary school teachers who will be responsible for the physical education of children in kindergartens and primary schools respectively do not receive appropriate training in adaptive physical education.

The aim of this article is to present a concept for introducing a training program on "Motor Activity Training and Inclusive Physical Education", intended for students of the specialty Preschool and Primary School Education at the Faculty of Education, Thrakia University, Bulgaria.
\end{abstract}

Key words: professional competence, adaptive physical education, children with special educational needs

\section{INTRODUCTION}

In the recent years Bulgaria's educational policy has been aimed at reducing the number of special educational establishments and increasing the number of children with special educational needs (SEN) involved in the general education environment.

The Pre-school and School Education Act, adopted in 2015, regulates the introduction of inclusive education. It is an integral part of the right to education and is the process of recognizing, accepting and supporting the individuality of each child or pupil and the variety of needs of all children and students by activating and involving resources aimed at removing the obstacles to studying and learning and to creating opportunities for the

\footnotetext{
*Correspondence to: Galena Terzieva

Faculty of Education, Trakia University - Stara

Zagora,Bulgaria, gtterzieva@abv.bg
}

development and participation of children and pupils in all aspects of community life (1).

Physical education and sport are an integral part of the educational process. All establishments should create conditions for exercising and sports for healing purposes, as well as conditions for practising physical exercise and sports for children with SEN (2).

The Inclusive Education Ordinance of 2017 sets out the state education standard for inclusive education. Children with impaired vision, impaired hearing, physical disabilities, mental retardation and multiple disabilities should be educated on the general educational subject "Physical Education and Sports / Medical Physical Education". This implies organizing activities in sparing and recovery routine (3) that provides physical exercise appropriate to their capabilities and health and integrates them in the class or group (4). 
The issue of implementing inclusive physical education or adapted physical education in inclusive conditions is at the forefront. It is a combination of children with different abilities within the framework of general physical activity. To accomplish this, the physical education teacher must make the necessary didactic, pedagogical and programmatic changes and provide all children with the opportunity to achieve their goals, to have a sense of security, convenience and success in the conditions of exercising motor activity (5).

Since the most characteristic peculiarity and feature of the activity in physical education is the active motor activity of the students and related with that physical activity (6), adapting it to the specifics of children with different disabilities requires more specific training. Analysis of the curricula of pedagogical faculties shows that students in the specialty Pre-school and Primary-school Education do not receive training on Adapted Physical Education (APE). Thus, in practice, future preschool and primary teachers who will lead classes in physical education do not acquire competences for inclusion of children with SEN in them during their studies.

\section{PURPOSE}

The aim of the article is to present a concept for a training program on "Motor and Inclusive Physical Education" to overcome these deficits. It is designed for students from the specialty Pre-school and Primary School Education at the Faculty of Education, Trakia University, Bulgaria.

\section{METHODS}

The following methods have been used to structure the program: documentary research method, comparative method, analysis and synthesis.

\section{RESULTS}

The training takes place during the winter semester of the fourth course with 30 hours of work - 12 hours of seminars and 18 hours of practical exercises. Through the training the participants receive advanced and in-depth knowledge in the area of Adapted Physical Education, master skills for modification and adaptation of the physical education process, taking into consideration the specifics of the children with SEN, and are prepared for pedagogical work in the sphere of inclusive physical education. Additionally, positive attitudes and a high level of confidence in their
TERZIEVA G. own ability to integrate children with SEN in motor training are formed.

The training program consists of four modules - target-resultant, meaningful, organizational and evaluative-resultant.

1) The main purpose of the course described in the target-output module is the formation of knowledge and skills in the field of APE and readiness to apply them in practice for the successful inclusion of children with SEN in motor training. Hence its tasks, which are aimed at:

- creating ideas about the character and trends in the development of APE and Adapted Physical Activity, acquaintance with examples of good practices;

- forming knowledge about the guiding principles of adapting the content of physical education in the kindergarten and elementary school according to the capacities of children with SEN and skills for their application in practice;

- acquiring theoretical and methodological knowledge in the field of APE, understanding the specifics of the content of the exercises and the methodology of selection and appropriate modification of physical exercises, mobile games and sports for children with SEN;

- building knowledge and skills base for planning, organizing and conducting physical education in which children with SEN are involved;

- acquiring knowledge and skills for control and assessment of SEN children in motor training;

- learning about means of communication with children with SEN, teamwork with their parents and various APE-related specialists;

- the formation of positive attitudes and high self-efficacy for the inclusion of children with SEN in organized forms of physical education.

2) The information of the content module provided to the students is based on the research of leading American, European and Bulgarian scientists. The content is divided into two blocks.

The first block is theoretical and introductory and aims to get students familiar with the characteristics of the APE. The main topics included in this block are related to the nature of the APE and its relationship to the other three types of APE. Its main functions are clarified and its aims are outlined as a factor in the development, rehabilitation and inclusion of people with disabilities. The pedagogical 
and specific principles of APE are revealed, the tasks are structured and the resources are classified. The possible modifications and adaptations of the physical education methods are explained in view to their use for inclusion of children with SEN in the motor training. The roles of parents and different specialists are pointed out regarding the participation of children with SEN in physical education in a mass educational environment.

The second block is with practical application and is divided into six parts depending on the disability or illness of children (visual impairment, hearing impairment, physical impairment, mental retardation, autism and attention deficit hyperactivity disorder). Its main objective is to familiarize students with the characteristics of children according to the deprivation, the specificities of the APE methodology in each of them and the formation of skills for preparation and carrying out physical education, including a child with the respective disability.

3) The organizational module is related to the optimal combination of the forms of organization of employing the students and the appropriate training methods in order to achieve a higher degree of learning of the taught material.

At the stage of forming new knowledge in the field of APE, verbal and visual methods are combined with a presentation. The lecturer's oral presentation is combined with rich visualization through pictures, drawings, pictures, audio and video materials, as well as demonstration of concrete actions. This implies the availability of appropriate technical means - a computer, a multimedia projector, an interactive whiteboard. Students are required to perceive, understand and remember the information provided.

At the stage of solidification of the studied material, different methods are combined, which imply greater activity on the part of the students. They are organized in the form of simulation-based pedagogical training. It unfolds on a broad theoretical-pedagogical basis and through the discussion and solving of a number of cases, skills from nearby areas (7) - physical education and inclusive education are transferred and the skills for adapting the content of physical education are built and developed. This creates an interactive, interdisciplinary environment in which the learner actively participates in the
TERZIEVA G.

professional-pedagogical reality (8). Prerequisites are created for the accumulation of knowledge and experience in the field of APE, which in turn will lead to the formation of positive attitudes and a high level of selfefficacy for inclusion of children with SEN in motor training (8-11).

4) The evaluation-outcome module is aimed at assessing students' achievements at the end of the training. They are expected to have formed:

- knowledge of the essence, functions and principles of the APE; about the tasks, means and methods of the APE; about the physical and mental characteristics in the development and functioning of the body of children with different disabilities; on the guiding principles for adapting motor skills; on the possibilities of adapting elements of the physical education curriculum so as to include children with different disabilities; for alternative and complementary means of communication with children with SEN in physical education; the methods for controlling and evaluating the results of the APE; for the role of the different specialists (healthcare provider, special pedagogue, sports professional) with regard to the APE; on the role of parents of children with SEN in relation to APE;

- skills for formulating the objectives of the APE as a factor for the development, rehabilitation and inclusion of children with SEN; to adapt the place of physical education and the necessary equipment and facilities for the successful inclusion of children with SEN; to adapt the tasks for each physical education activity involving a child with SEN; to use accurate terminology and to demonstrate properly and appropriately physical exercises; to adapt teaching methods that take into account the individual characteristics of each child with SEN in physical education; to adapt the tools for checking and evaluating (diagnosing) the achievements of children with SEN; organizing and controlling activities during teaching to ensure the most appropriate and safe motor training for all children, including children with SEN; supporting the inclusion of children with SEN in motor training by initiating and organizing different forms of interaction, building relationships based on mutual trust and respect; preparing school staff to support the inclusion of children with SEN in motor training;

- competencies related to knowledge and skills about the theoretical aspects of the APE; for planning of forms of physical education with inclusion of a child with SEN; to organize and 
manage the educational process of physical education with the inclusion of a child with SEN; to assess the progress of children with SEN on physical education; to manage processes in separate groups or classes during physical education involving a child with SEN; related to knowledge and skills for team work with the parents of children with SEN and with various specialists related to their motor training.

\section{CONCLUSIONS}

The introduction of training related to the inclusion of children with SEN in the organized forms of physical education for the students of pre-school and primary school pedagogy will contribute to the formation of professional competences in this field, which will be necessary for their successful future realization in the conditions of the modern kindergarten and elementary school.

\section{REFERENCES}

1. Pre-school and School Education Act. SG 79/13.10.2015, effective 01.08.2016

2. Law on Physical Education and Sports SG. $58 / 09.07 .1996$, and subsequent updates

3. Georgieva D., Katsarska V. Sparing and Recovery Routine in The Training and Rehabilitation of Students With Special Educational Needs. The II nd International Scientific and Practical Conference "World Science". Topical Problems of Modern Science and Possible Solutions, 10 (14), Vol.5, pp. 5-8, 2016

4. Inclusive Education Ordinance from 2017. SG 86/27.10.2017, effective 27.10.2017

5. Kudláček, M., Válková, H., Sherrill, C., Myers, B., French, R. An inclusion instrument based on planned behavior
TERZIEVA G.

theory for prospective Czech physical educators. Adapted Physical Activity Quarterly, 19, pp. 280-299, 2002

6. Boeva, B., Ivanova, V. Theory and methodology of the physical education. Manual for the students from Trakia University. Theoretical and methodological principles of the physical education. Part one. Stara Zagora, 2018

7. Petrov, P.D., Temnikova, M. Regarding transferability of the skills and the competency and their development in the course of education in mathematics in the primary school. Central Bohemia University Czech Republic, International conference proceedings, p. 845, 2017

8. Neminska, R. Simulation-based pedagogical training. KOTA, Stara Zagora, pp. 70-75, 2015

9. Petkova, A., Kudláček, M., Nikolova, E. Attitudes of physical education students (last university year) and physical education teachers toward teaching children with physical disabilities in general physical education classes in Bulgaria. European Journal of Adapted Physical Activity, 5(2), pp 82-98, 2012

10.Tindall, D., Culhane, M., Foley, J. Preservice teachers' self-efficacy towards children with disabilities: An Irish perspective. European Journal of Adapted Physical Activity, 9(1), pp. 27-39, 2016

11.Block, M., Healy, S. Kwon, E. H., Ruin, S., Volkmann, V. Können Haltungen und Verhalten verändert werden? Der (internationale) Diskurs um Adapted Physical Education in der Sportlehrerbildung. Sonderpädagogische Förderung heute, 62 (3), pp. 255-265, 2017 